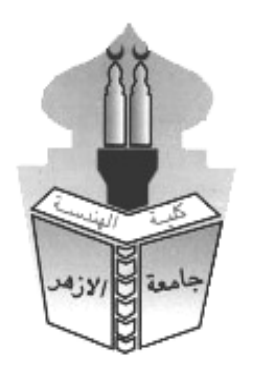

\title{
ELASTIC BUCKLING AND ULTIMATE LOAD OF PORTAL FRAMES
}

\author{
Farah El Dib \\ Institute of Metallic Construction, Building Research Center, Giza, Egypt. \\ E-mail: farah fayrouz@yahoo.com
}

\begin{abstract}
Existing portal frames were often built for industry using an extensive amount of material. The buckling and the ultimate loads are thus crucial values often determined assuming concentrated loads on top of the columns. Usually, the frames carry distributed loads that always create primary moments, in addition to compressive forces transferred from the supports to the beams, which may reduce the buckling load. This paper investigates the accurate buckling and the ultimate load behavior of portal frames.

The analysis uses different loading patterns in addition to different methods of analysis, and also takes into consideration big deformations. The investigations use both analytical, 2-D and a 3-D Finite Element Analysis (FEA) to ensure the validity and accuracy of the results. An approximate method in addition to the accurate numerical method is given. The limitations, accuracy, and validity of the proposed method are found, and design precautions and recommendations are also given.
\end{abstract}

\section{KEYWORDS: Portal frames, Buckling, Ultimate Load, Design Aids, FEA.}

$$
\begin{aligned}
& \text { الانبعاج المرن والحمل الأقصى بإطارات البوابات } \\
& \text { فرح الــليب } \\
& \text { معهد المنشآت المعدنية ، مركز أبحاثِ البناء ، الجيزة ، مصر }
\end{aligned}
$$

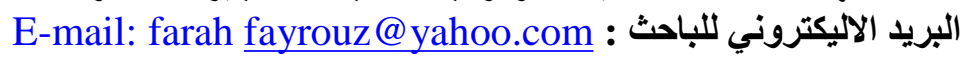

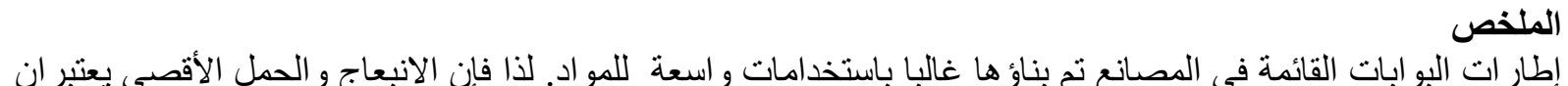

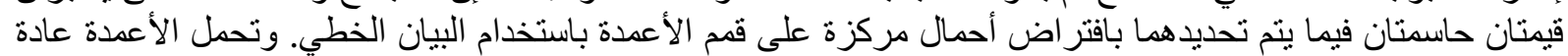

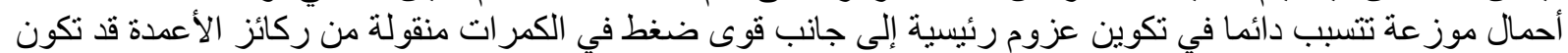

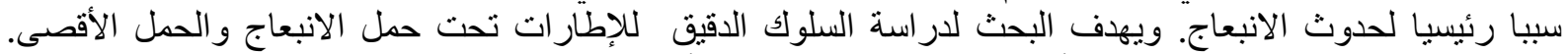

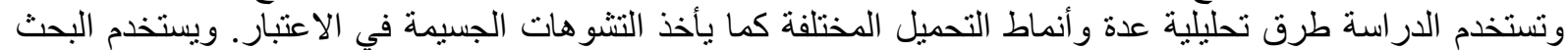

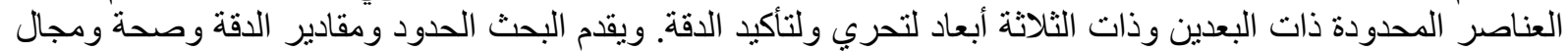

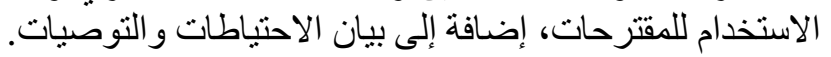

الكلمات المفتاحية : إطارات البوابات ، الانبعاج ،الحمل الأقصى ، مساعدات التصميم ،العناصر المحدودة

\section{INTRODUCTION}

Hellesland [1] showed that the buckling modes of compression members in a frame can be associated with both positive and negative end restraints. Bridge and Fraser [2] gave effective length diagrams that cover both positive and negative rotational restraints for braced members. 
Hellesland and Bjorhovde [3] introduced an alternative approach that allows the same restraints. Salem et al.[4] have covered laterally or partially un-braced frames. Hellesland [5,6] and the Design Aids prepared at HBRC [7], developed approximate effective length formulas and charts, respectively, to be applied in the system instability analysis of frames. Eurocode 3 [8] relies on the effective length method to assess the stability of multi-story frames. Webber et al. [9] introduced an improvement to the method given in the Eurocode 3 where the axial load in adjoining columns is considered. El Dib [10] and Gindy [11] have made surveys of previous research in buckling of columns and frames. Salem et al. [12] presented a solution for frames under unsymmetrical beam loads using a numerical analysis. A computer program was written to describe the stiffness matrix of the frame under a concentrated load traveling from one end of the girder to the other. In this research a finite element analysis is conducted to find the accurate buckling and ultimate loads of portal frames with distributed loads on their girders.

\section{ASSUMPTIONS, VERIFICATION, AND ACCURACY}

In the first analytical method presented, the equilibrium conditions for the deformed system are written, then the determinant of the stiffness matrix is set equal to zero, and the lowest value of the buckling load is iteratively determined. In the second method, the finite element analysis (FEA), which was done using the ANSYS program [13], the finite elements, "Beam3" and "SHELL 181", were used as they are accurate and both allow for large deformations.

In the first case: concentrated loads are placed on the top of the columns. In the second case: distributed loads are applied on the frame, and the elastic critical loads are determined numerically. In the third case: distributed loads are applied, but an elastic analysis is carried out allowing for large deformations. Then the maximum possible loads are determined, which leads to more realistic K-Values being given directly, which avoids loss of safety. In the fourth case: the ultimate load of long-span portal frames is determined numerically using a 3-D FEA allowing for large deformations. Geometrical, as well as material non-linearity, are considered. An approximate interaction formula that uses the correct parameters is applied. All results are compared with the corresponding ones and conclusions are made.

\section{CASE I: CONCENTRATED LOADS ON COLUMNS}

The loading pattern \#1 consists of two similar columns connected to upper and lower beams with different rigidities $\boldsymbol{k}_{\boldsymbol{A}}$ and $\boldsymbol{k}_{\boldsymbol{B}}$. The symmetrical mode of buckling, and the swaying one are shown in Figure 1. The primary normal forces in the beams "AD" and "BC" are null.

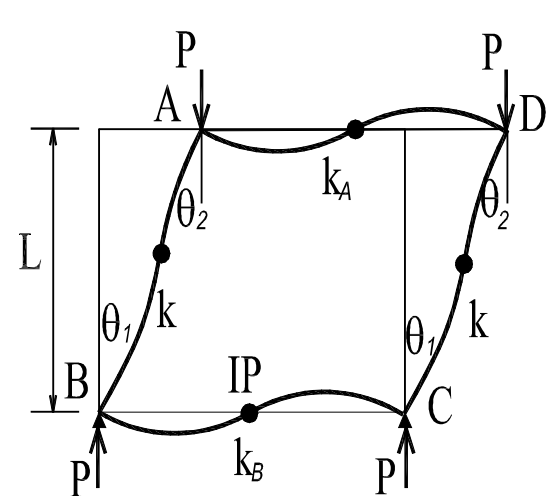

a. Sway Mode

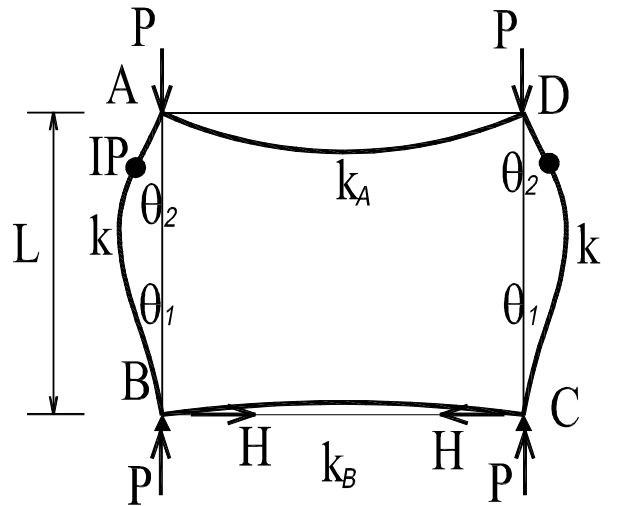

b. Symmetrical Mode

Figure 1: The loading pattern \#1.

The rigidity ratio at the lower corner GB is the ratio between column stiffness to lower beam stiffness $\mathrm{k} / \mathrm{k}_{\mathrm{B}}$, and GA is referred to as the rigidity ratio of the upper corner $\mathrm{k} / \mathrm{k}_{\mathrm{A}}$, where $\mathbf{k}$ is equal to EI/L and I, is the moment of inertia of the column. The system is perfectly elastic, the buckling is planar and local buckling is prevented, the written determinant is set to zero: 


$$
\left|\begin{array}{cc}
n+6 / G A & -o \\
-o & n+6 / G B
\end{array}\right|=0
$$

The buckling length multiplier is $\mathrm{K}=\pi /(\mu \mathrm{L})$, where $\mathrm{O}=\mu \mathrm{L} / \sin \mu \mathrm{L}, \mathrm{n}=\mu \mathrm{L}$ cos $\mu \mathrm{L}$ and $\mathrm{m}=2(1-\cos \mu \mathrm{L}) /(\mu \mathrm{L} \sin \mu \mathrm{L})$. The evaluation of Equation 1 controls the accuracy of the numerical solution that is carried out by dividing the frame into 26 Beam3-Elements. By using an iterative procedure, the buckling length multiplier $\mathrm{K}$ is calculated from Equation 1 .

The results are compared with the FEA-results. For $\mathrm{GB}=1$ they are higher by $0.2-1.7 \%$; however, this difference is justified as the theoretical solution makes no consideration of the deformations due to normal and shear forces that are considered in the FE stiffness matrix. When the cross-sectional area of the FEA is given a high value, and is input as $10 \mathrm{~m}^{2}$, this difference becomes less than $10^{-4}$. This comparison confirms the accuracy of the selected parameters in the numerical solution, however, the determination of the K-value considering the actual areas of the cross-section is more realistic and is on the safe side.

\section{CASE II: DISTRIBUTED LOAD ON BEAM}

In this case the analysis is made numerically. The distributed load on the beam is designated as the loading pattern $\# 2$, and it is taken equivalent to the total load on the two columns as assumed in Case I, such that its value equals 2P/B. It creates a primary force $\mathrm{H}$ in the lower beam, and the buckling length multiplier $\mathrm{K}$ is higher. This beam compressive force becomes much higher in frames with short columns and/or with long spans.

$$
\begin{gathered}
M_{1}=n k \theta_{1}-o k \theta_{2}-m \frac{F L}{2} \\
\frac{\delta_{1}+\delta_{2}}{L}=\frac{1}{s(1+c)} m \frac{F L}{2 k}+\frac{m}{2}\left(\theta_{1}+\theta_{2}\right)
\end{gathered}
$$

Figure 2: Resolution of general state of sway of intermediate column.

Considering Figure 3, two inflection points IP are created within the beam length. The loaded beam is, therefore, overturning the upper joints and the columns are now resisting bowing, which has a negative effect on the buckling capacity. In this case, the ratio $\mathrm{B} / \mathrm{L}$ becomes a crucial buckling parameter, and it is assumed to be between 0.5-6. The buckling behavior of the system in Figure 3 is guided by the type of loading. By increasing the load $\mathrm{P}$ on the beam, the vertical beam deflection $\delta, \square \square$ shown in Figure 4, can be described with the curve A that is running towards a higher symmetrical buckling load, which is not the least eigenvalue. The least eigenvalue represents a bifurcation buckling given by line B. The smooth approach, curve $\mathrm{C}$ may only be achieved by applying a horizontal disturbing force at the top of the frame. Note that $(\delta) \square$ represents the vertical deflection in the beam at mid-point. 


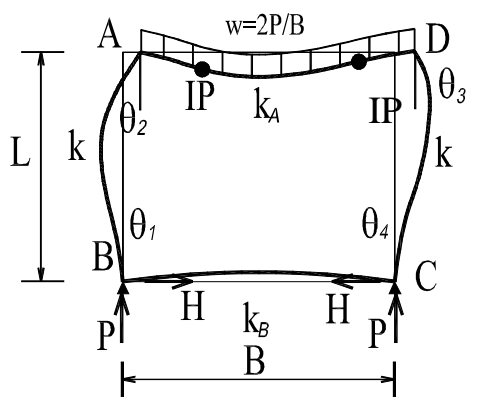

Figure 3: The loading pattern \#2: Case II.

The corresponding buckling modes of cases A and B together with the deformation shape of case $\mathrm{C}$ are given in Figure 5. For loading pattern \#2, no Bowing Functions are available for the beam-columns, nor for the beams with lateral loads in addition to compressive force.

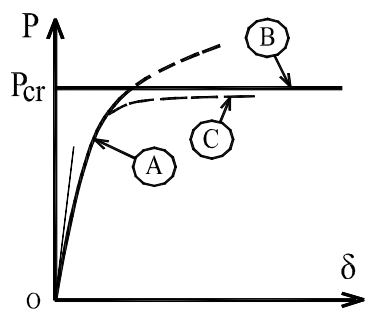

Figure 4: The buckling behavior: Case II.

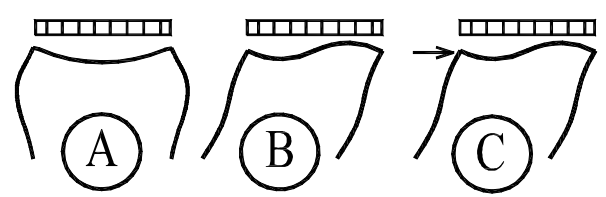

Figure 5: The corresponding mode shapes and deformations to Figure 4 (loading pattern \#2, Case II).

The verification is done, and the accuracy is checked, by comparing the analytically found buckling load-values with the numerically calculated limit case where $\mathrm{B} / \mathrm{L}$ is small. In this case, the buckling load in case I, which is analytically verified, is a close upper bound to that in case II and the $\mathrm{K}$ value is its lower bound. The $\mathrm{K}$ values in Table 1 that are calculated in Case I represent the lower bound of those considering the distributed loads of Case II. The comparison shows that these values are accurate.

Table 1: Comparison between the Cases I and II $(G B=1, B / L=0.5)$.

\begin{tabular}{|c|c|c|c|}
\hline GA & $\begin{array}{c}\text { K: FEA } \\
\text { Case I }\end{array}$ & $\begin{array}{c}\text { K: FEA } \\
\text { Case II }\end{array}$ & $\begin{array}{c}\text { Diff } \\
\%\end{array}$ \\
\hline 1 & 1.33964 & 1.34009 & 0.03 \\
\hline 5 & 1.70918 & 1.71285 & 0.21 \\
\hline 10 & 1.90716 & 1.91290 & 0.30 \\
\hline
\end{tabular}

\section{CASE III: NON-LINEAR SOLUTION}

Figure 6 represents the numerical modeling of the investigated portal frame. Each column is divided into 8 elements and the beam into 20 elements of the type (Beam3). The sum of the 
vertical loads $=2 \mathrm{P}$. The bottom stiffness ratio is $\mathrm{GB}$, and the upper stiffness ratio is $\mathrm{GA}=\mathrm{k} / \mathrm{k}_{\mathrm{A}}$, where the column rigidity is $\mathrm{k}=\mathrm{EI}_{\mathrm{C}} / \mathrm{L}$, and $\mathrm{k}_{\mathrm{A}}=\mathrm{EI}_{\text {Beam }} / \mathrm{L}$.

A small horizontal force at the top of the frame triggers the non-linear deformations. It creates a smooth transition between the two buckling modes in Figure 4, prevents bifurcation and gives conservative results. The validity and accuracy of the non-linear elastic FEA are checked and compared with the Euler elastic load. This numerical solution considers severe non-linearity caused by large deformations, adds them to the original geometry while considering the elongation, or contraction in each element. The aim is to capture any deviation of the eigenvalue found in Case II, from realistic behavior of portal frames.

The resulting load-deflection (FEA) relationships are displayed in Figures 7 and 8. Plotted are the sway deformation with respect to the column height, and the vertical beam deflection at mid-span related to the beam length. For all cases, the least eigenvalue critical elastic buckling load is determined according to the loading pattern \#2. The ordinate in all cases represents the load variation related to this critical load.

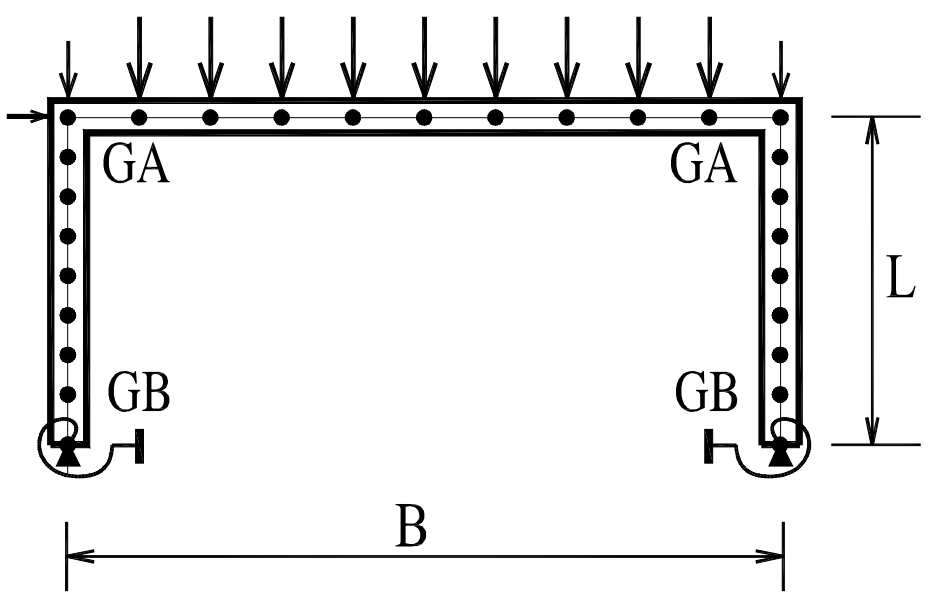

Figure 6: The system and the loading pattern \#2 of the numerical solution.

When increasing B/L in Figure 7, the critical load cannot be reached. The limit load values for $\mathrm{B} / \mathrm{L}=3.5$ and 5.0 are about 0.6 and $0.4 \mathrm{P}_{\mathbf{c r}}$ respectively. Any increase in the limit value reduces the limit load below $\mathrm{P}_{\mathbf{c r}}$, as in the cases captured in Figures $7 \mathrm{a}$ and $7 \mathrm{~b}$. It is worth noting that the P- $\Delta x / L$ curve always starts tangential to the vertical, while the $P-\Delta y / B$ curve begins tangential to the initial linear primary bending stiffness.

\section{EVALUATION AND RESULTS OF NON-LINEAR ANALYSIS (FEA)}

The numerical model is evaluated for the following parameters and assumptions: elastic deformations: $\mathrm{GB}=10, \mathrm{~B} / \mathrm{L}=1$ to 6 . All deformations are in the frame's plane, and no local buckling is considered. An important goal of the analysis is to capture differences between the buckling loads found at the least eigenvalues, and the non-linear elastic buckling behavior. In addition to this investigation, a manual search is repeated to capture the limit $\mathrm{B} / \mathrm{L}$ values.

A sample of the results is plotted together in Figure 8 for the case of a hinged base. The dashed horizontal lines represent the initial buckling length multiplier. These K-values of the initial buckling load are not dependent on the frame span. In this initial case, the beam is free from primary compressive forces. Note that

$$
K=\sqrt{\frac{P_{e}}{P_{c r}}}, \quad P_{e}=\frac{\pi^{2} E I}{L^{2}},
$$


where $\mathrm{L}$, is the column height.

The solid lines, in Figure 8, represent the solution according to Case I. These values increase remarkably by increasing the frame span ratio $\mathrm{B} / \mathrm{L}$ and/or the GA value. High $\mathrm{B} / \mathrm{L}$ and/or GA indicate less beam rigidity in addition to increased compression in the beam. Nevertheless, $\mathrm{B} / \mathrm{L}$ values beyond the limit values, designated by the filled points, deliver unrealistic KValues on account of the design safety. Such a decrease in safety is considerable in slender frames.

The limit $\mathrm{B} / \mathrm{L}$ values, found by the manual repetition of numerical runs until $90 \%$ of $\mathrm{P}_{\mathrm{cr}}$ is reached, are given in Table 2 for $\mathrm{GB}=1.0$, and displayed in Figure 8 for $\mathrm{GB}=10$.

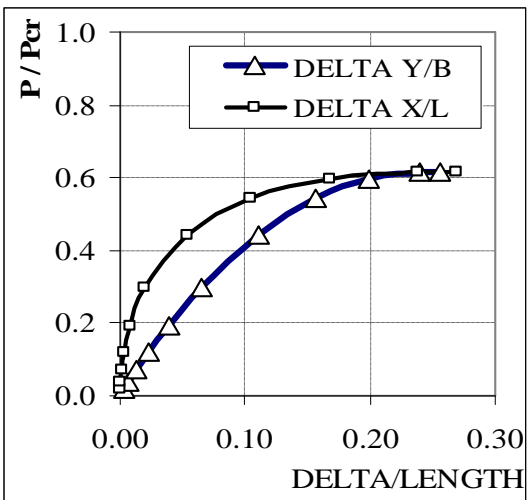

a) $\mathrm{B} / \mathrm{L}=3.5$

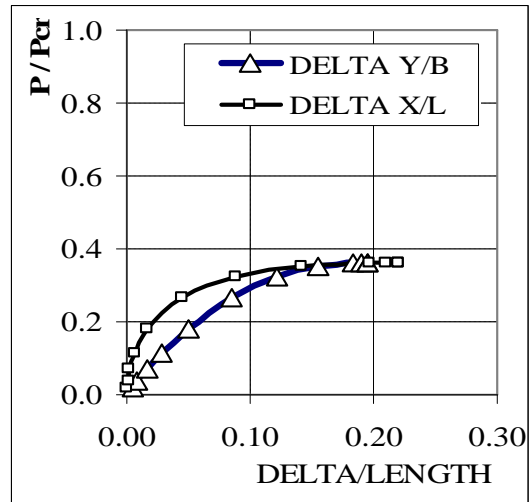

b) $\mathrm{B} / \mathrm{L} \mathbf{5 . 0}$

Figure 7: $\mathrm{P}-\Delta$ for $\mathbf{G A}=\mathbf{5}, \mathbf{G B}=\mathbf{1 0}$.

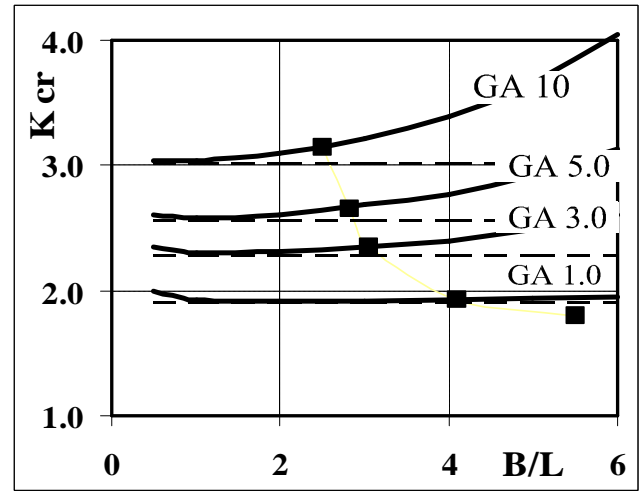

Figure 8: Variation of the buckling length multiplier " $K$ " versus $B / L(G B=10.0)$.

Table 2: Limit B/L (GB=1.0).

\begin{tabular}{|c|c|c|c|}
\hline 1 & 2 & 3 & 4 \\
\hline $\mathrm{GA}$ & $\mathrm{B} / \mathrm{L}$ & K-Value & $\mathrm{I}_{\mathrm{A}}$ \\
\hline 0.5 & 3.57 & 1.245 & 0.140 \\
\hline 1.0 & 2.68 & 1.331 & 0.373 \\
\hline 3.0 & 2.03 & 1.594 & 1.478 \\
\hline 5.0 & 1.88 & 1.759 & 2.660 \\
\hline
\end{tabular}

\section{THE ULTIMATE LOAD OF LONG SPAN FRAMES}

The following assumptions are applied throughout the analysis:

- The buckling is in plane of analysis. No lateral and local buckling

- $\quad$ The material is perfectly elastic-plastic. 
- $\quad$ The yield spread is assumed in both normal and shear stresses.

- $\quad$ The load is distributed over the beam length.

- Geometrical imperfections of $\mathrm{h} / 500$ are assumed relative to the least eigenvalue of the first sway mode (Figure 9).

In Table 3, the selected column and beam sections are stated. Large deformations are considered. The flanges and the web of the beam and the column are divided into elements having dimensions of not more than 70 mms. The "ANSYS" finite element "SHELL 181" is used. It allows for yield spread in the normal stresses as well as in shear.

Special consideration is given to the shear yield at the corner of the frame. If omitted, a CORNER PLASTIC SHEAR HINGE may be created as given in Figure 10. In case the corner web triggers the failure, the total distributed ultimate load value is considerably reduced, up to $32 \%$ as given in case \#3 of Table 4 . To avoid a corner plastic shear hinge formation the following formula should be applied:

$\frac{M_{P L}}{V_{\mathrm{Corn}, W}}-\frac{M_{P L}}{L_{\mathrm{Col}, \mathrm{Net}} . A_{\mathrm{Corn}, \mathrm{Web}}}<\frac{F_{y}}{\sqrt{3}}$,

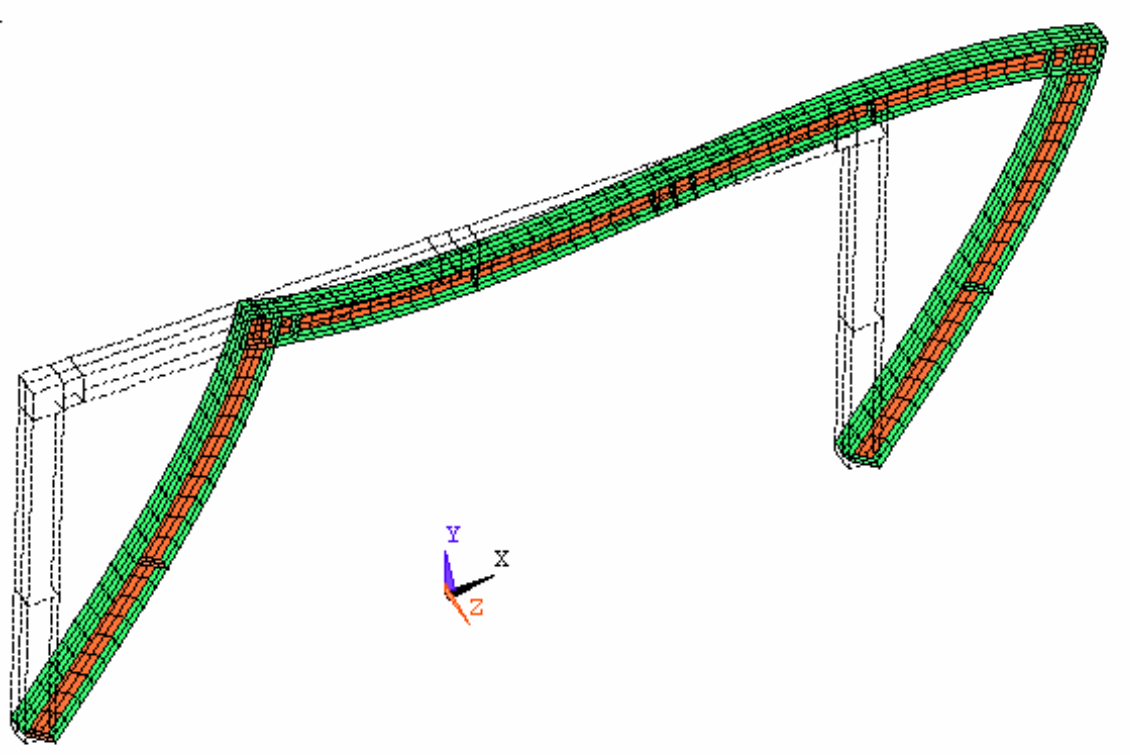

Figure 9: The sway buckling mode.

where $M_{\mathbf{P L}}$ is the smaller plastic moment value of column or beam sections, $\mathrm{V}_{\mathbf{C o n n}, \mathbf{W}}$ is the volume of the rectangular corner web between the stiffeners, $\mathrm{L}_{\mathrm{Col}, \mathrm{Net}}$ is the net length of the column, and $A_{\text {Corn,Web }}$ is the corner web area perpendicular to the column length. For design, replace $M_{\mathbf{P L}}$ by the factored load and insert the resistance factor on the right-hand side.

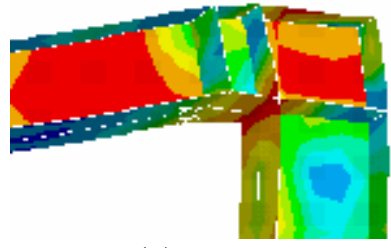

(a)

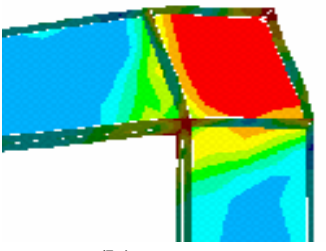

(b)

Figure 10: Examples plastic shear hinge. 
The required ultimate load is obtained due to excessive yield spread mainly due to normal stresses in frame column and/or beam. It is used to apply and verify the formula in the ECPLRFD Code [14] Chapter 7.

By taking $\phi$ and $\phi_{b}=1.0$, and by searching $P_{\mathbf{u}}$ and $M_{\mathbf{u}}$, given by linear statics of the distributed load on the frame's beam, and fulfilling the right-hand side $=1.0$, the approximate value of the ultimate load is found, which represents the analytical solution. It can be directly compared with the ultimate load, found from the numerical accurate solution.

Two frame types are selected: Type A, $\mathrm{L}=6 \mathrm{~m}$ and $\mathrm{B}=24 \mathrm{~m}$ with loading pattern \#2 and Type $\mathrm{B}, \mathrm{L}=6 \mathrm{~m}$ and $\mathrm{B}=36 \mathrm{~m}$ with loading pattern \#3. These dimensions are outer dimensions as illustrated in Figure 11.
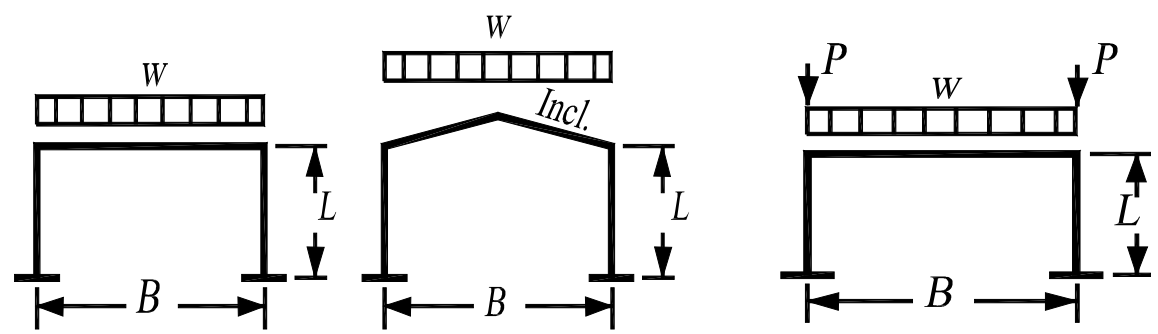

a) Loading pattern \#2.

Figure 11: Loading types.

It should be noted that the corner frame moment is determined by applying the ultimate load, found by means of the FEM, on the frame and then the corner moment is calculated assuming LINEAR elastic frame behavior, as given when designing such a frame. This value represents the factored load, which examines the code interaction formula.

Column \#6, in Tables $4 \& 5$, is found by searching the load value in the ECP-LRFD [14], Chapter 7, which results in the right-hand side becoming equal to unity. Since the interaction equation is non-linear with respect to the load, thus the calculated ultimate load must be found either by solving the $2^{\text {nd }}$ degree equation, or iteratively. By applying the value $715.3 / 2=357.65$ $\mathrm{kN}$ of case \# 3 in Table 4, we get:

$$
\frac{357.65}{2 * 2784}+\frac{0.85 * 1180.5}{1169.6\left[1-\frac{357.65}{4295}\right]}=1.000 \text {. }
$$

The frame, given in case \# 3, is illustrated while under ultimate load that is found by means of the FEA in Figure 12, which shows the whole frame with magnified deformations. Figure 13 shows the most critical part that usually triggers the ultimate load: the frame corner. No shear plastic hinge is created since the thickness of the corner plate is taken big enough to prevent the formation of the shear yield.

In Table 3, the selected column and beam sections are stated. Column \#1 gives the crosssectional dimensions: $\mathrm{h} / \mathrm{b} / \mathrm{t}_{\mathbf{F L}} / \mathrm{t}_{\mathbf{W e b}}$. Each section type is indicated in column \#2 of Table 4.

The subscript of the cross-section type; Table 3 indicates the frame part that uses this section: beam or column. The ultimate loads due to loading pattern \#3 are given in Table 5 , in which the results are arranged similar to Table 4, with the exception of Column \#3. In this column, the ratio of distributed load to the total load $[w L /(w L+2 P)]$ is stated. This type of loading is examined for a frame span B that is six times larger than the height $\mathrm{L}$. 


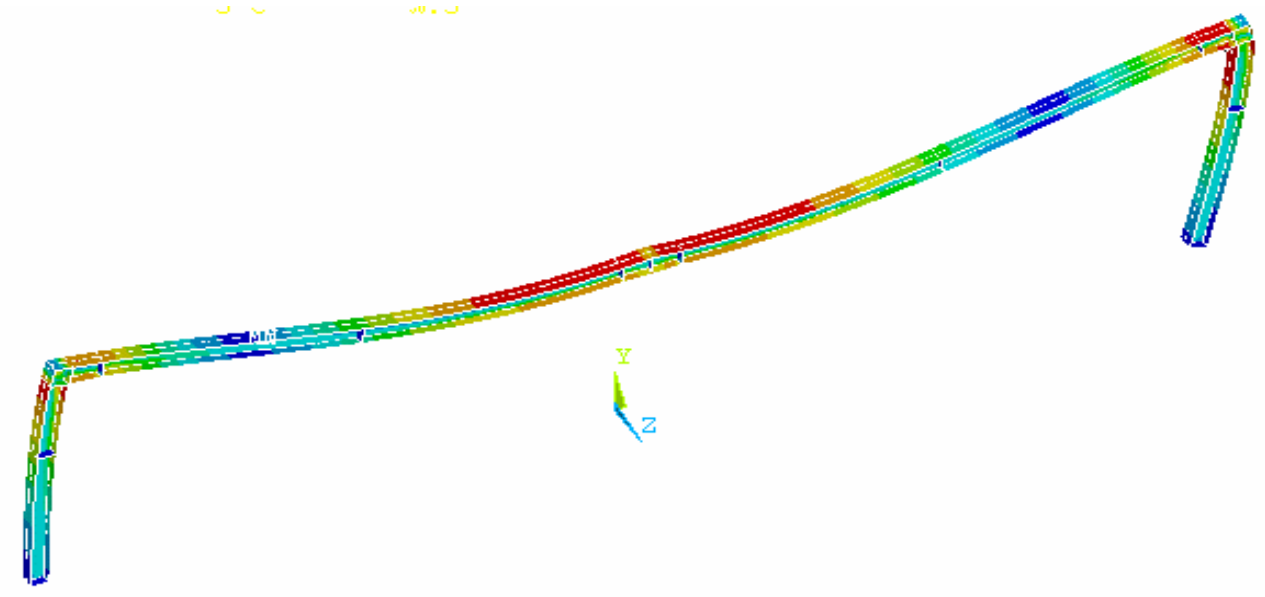

Figure 12: Case \#3, Table 4: ultimate load, magnified deformations.
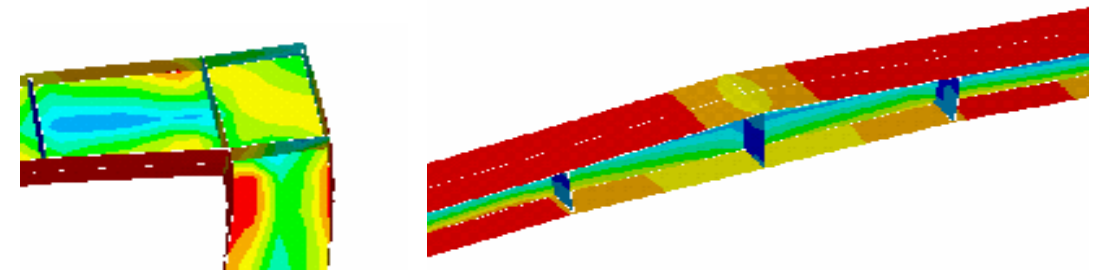

Figure 13: Case \#3, Table 4: ultimate load, corner and apex stresses (von Mises).

Table (3): Frame cross section dimensions and properties.

\begin{tabular}{|c|c|c|c|c|c|}
\hline Type & Dims (mms) & $\begin{array}{c}\mathbf{M}_{\mathbf{P L}} \\
\mathrm{kN.m}\end{array}$ & $\begin{array}{c}\mathrm{A} \\
\mathrm{mm}^{2}\end{array}$ & $\begin{array}{c}\mathrm{I}_{\mathbf{x}} \\
\mathrm{mm}^{4}\end{array}$ & $\begin{array}{c}\mathbf{r}_{\mathbf{x}} \\
\mathrm{mm}\end{array}$ \\
\hline & 1 & 2 & 3 & 4 & 5 \\
\hline $\mathrm{I}_{\mathbf{b}}, \mathrm{II}_{\mathbf{b}}$ & $400 / 400 / 25 / 12.5$ & 991.9 & 24375 & $7.478 .10^{\mathbf{8}}$ & 175.2 \\
\hline $\mathrm{I}_{\mathbf{C}}, \mathrm{II}_{\mathbf{C}}$ & $400 / 400 / 30 / 12.5$ & 1152.3 & 28250 & $8.623 .10^{\mathbf{8}}$ & 174.7 \\
\hline $\mathrm{III}_{\mathbf{b}}, \mathrm{IV}_{\mathbf{b}}$ & $400 / 400 / 25 / 15$ & 1010.3 & 25250 & $7.567 .10^{\mathbf{8}}$ & 173.1 \\
\hline $\mathrm{III}_{\mathbf{C}}, \mathrm{IV}_{\mathbf{C}}$ & $400 / 400 / 30 / 15$ & 1169.6 & 29100 & $8.705 .10^{\mathbf{8}}$ & 173.0 \\
\hline $\mathrm{V}_{\mathbf{b}}, \mathrm{VI}_{\mathbf{b}}, \mathrm{VII}_{\mathbf{b}}, \mathrm{VIII}_{\mathbf{b}}$, & $300 / 300 / 20 / 12.5$ & 453.9 & 12250 & $2.535 .10^{\mathbf{8}}$ & 128.9 \\
\hline $\mathrm{V}_{\mathbf{C}}, \mathrm{VI}_{\mathbf{C}}, \mathrm{VII}_{\mathbf{C}}, \mathrm{VIII}_{\mathbf{C}}$ & $300 / 300 / 25 / 12.5$ & 541.9 & 18125 & $3.000 .10^{\mathbf{8}}$ & 128.6 \\
\hline $\mathrm{IX}$ & $500 / 500 / 40 / 20$ & 2419.7 & 48400 & $2.239 .10^{9}$ & 215.1 \\
\hline $\mathrm{X}$ & $300 / 250 / 20 / 15$ & 396.8 & 13900 & $2.180 .10^{\mathbf{8}}$ & 125.2 \\
\hline $\mathrm{XI}_{\mathbf{b}}$ & $300 / 200 / 16 / 15$ & 282.7 & 10420 & $1.531 .10^{\mathbf{8}}$ & 121.2 \\
\hline $\mathrm{XI}_{\mathbf{C}}$ & $400 / 200 / 20 / 15$ & 481.4 & 13400 & $3.471 .10^{\mathbf{8}}$ & 160.9 \\
\hline $\mathrm{XII}_{\mathbf{b}}$ & $300 / 300 / 20 / 20$ & 484.3 & 17200 & $2.645 .10^{\mathbf{8}}$ & 124.0 \\
\hline $\mathrm{XII}_{\mathbf{C}}$ & $350 / 300 / 30 / 20$ & 792.1 & 23800 & $5.014 .10^{\mathbf{8}}$ & 145.2 \\
\hline $\mathrm{XIII}_{\mathbf{b}}$ & $500 / 300 / 25 / 20$ & 1098.0 & 24000 & $9.980 .10^{\mathbf{8}}$ & 203.9 \\
\hline $\mathrm{XIII}_{\mathbf{C}}$ & $400 / 350 / 30 / 20$ & 1071.1 & 27800 & $7.842 .10^{\mathbf{8}}$ & 168.0 \\
\hline
\end{tabular}


Table 4: Accurate \& approximate ultimate loads (loading pattern \#2).

\begin{tabular}{|c|c|c|c|c|c|c|c|c|c|}
\hline $\begin{array}{c}\text { Case } \\
\#\end{array}$ & $\begin{array}{c}\text { Frame } \\
\text { Type }\end{array}$ & $\begin{array}{c}\text { X-Sec } \\
\text { Type }\end{array}$ & Incl. & $\begin{array}{c}\text { Buckl. } \\
\text { Tot. Load } \\
\mathrm{kN}\end{array}$ & $\begin{array}{c}\text { Tot. Ult. } \\
\text { FE Load } \\
\mathrm{kN}\end{array}$ & $\begin{array}{c}\text { Eq.11 } \\
\mathrm{kN}\end{array}$ & $\begin{array}{c}\text { Diff. } \\
\%\end{array}$ & $\begin{array}{c}\delta_{\mathrm{H}} \\
\text { Lin } \\
\mathrm{mm}\end{array}$ & $\begin{array}{c}\delta_{\mathrm{H}} \\
\mathrm{NL} \\
\mathrm{mm}\end{array}$ \\
\hline Col.\# & 1 & 2 & 3 & 4 & 5 & 6 & 7 & 8 & 9 \\
\hline 1 & B & I & 0.1 & 4870 & 537.3 & 458.2 & 14 & 43 & 36 \\
\hline 2 & B & II & 0 & 4610 & 463.5 & 419.3 & 9 & 15 & 5 \\
\hline 3 & A & III & 0.1 & 8590 & 810.4 & 715.3 & 11 & 29 & 21 \\
\hline 4 & A & IV & 0 & 8603 & 730.8 & 682.7 & 6 & 15 & 1 \\
\hline 5 & B & V & 0.1 & 1699 & 242.6 & 204.1 & 16 & 55 & 44 \\
\hline 6 & B & VI & 0 & 1497 & 204.4 & 184.7 & 10 & 19 & 12 \\
\hline 7 & A & VII & 0.1 & 2914 & 368.6 & 315.0 & 14 & 38 & 23 \\
\hline 8 & A & VIII & 0 & 2894 & 333.1 & 300.6 & 10 & 20 & 4 \\
\hline 9 & B & IX & 0 & 14570 & 1080.6 & 938.4 & 13 & 13 & 2 \\
\hline 10 & B & IX & 0.1 & 14975 & 1239.0 & 1020.6 & 17 & 34 & 30 \\
\hline 11 & A & IX & 0.1 & 25247 & 1840.7 & 1558.3 & 15 & 24 & 18 \\
\hline 12 & A & IX & 0 & 25373 & 1670.9 & 1489.1 & 11 & 13 & -1 \\
\hline 13 & B & X & 0 & 6869 & 847.1 & 775.1 & 8 & 13 & 7 \\
\hline
\end{tabular}

Table (5): Accurate \& approximate ultimate loads (loading pattern \#3).

\begin{tabular}{|c|c|c|c|c|c|c|c|c|c|}
\hline $\begin{array}{c}\text { Case } \\
\#\end{array}$ & $\begin{array}{c}\text { Frame } \\
\text { Type }\end{array}$ & $\begin{array}{c}\text { X-Sec } \\
\text { Type }\end{array}$ & $\begin{array}{c}\text { Distr. } \\
\text { Load }\end{array}$ & $\begin{array}{c}\text { Buckl. } \\
\text { Load } \\
\mathrm{kN}\end{array}$ & $\begin{array}{c}\text { Tot. Ult. } \\
\text { Load (FE) } \\
\mathrm{kN}\end{array}$ & $\begin{array}{c}\text { Tot. Ult. } \\
\text { Eq.11 } \\
\mathrm{kN}\end{array}$ & $\begin{array}{c}\text { Diff. } \\
\%\end{array}$ & $\begin{array}{c}\delta_{\mathrm{H}} \\
\text { Lin } \\
\mathrm{mm}\end{array}$ & $\begin{array}{c}\delta_{\mathrm{H}} \\
\mathrm{NL} \\
\mathrm{mm}\end{array}$ \\
\hline & 1 & 2 & 3 & 4 & 5 & 6 & 7 & 8 & 9 \\
\hline 13 & $\mathrm{C}$ & $\mathrm{X}$ & 0.02 & 2200 & 1806 & 1082 & 40 & 1.9 & 1.2 \\
\hline 14 & $\mathrm{C}$ & $\mathrm{XI}$ & 0.10 & 1619 & 955 & 598 & 37 & - & - \\
\hline 15 & $\mathrm{C}$ & $\mathrm{XII}$ & 0.50 & 2139 & 454 & 417 & 8 & 1.3 & 1.3 \\
\hline 16 & $\mathrm{C}$ & $\mathrm{XIII}$ & 0.50 & 6868 & 847 & 776 & 8 & 1.3 & 0.7 \\
\hline 17 & $\mathrm{C}$ & $\mathrm{X}$ & 0.75 & 1283 & 240 & 238.1 & 0.8 & 1.5 & 0.05 \\
\hline 18 & $\mathrm{C}$ & $\mathrm{X}$ & 0.98 & 1298 & 178.3 & 154.0 & 13 & 5.5 & 4.4 \\
\hline 19 & $\mathrm{C}$ & $\mathrm{X}$ & 1.00 & 1183 & 166.1 & 138.9 & 16 & 5.5 & 4.4 \\
\hline
\end{tabular}

\section{SUMMARY AND RECOMMENDATIONS}

Three different loading patterns are applied on a portal frame, which is solved by means of three different methods: the concentrated loads on the columns (Case I), the distributed load on the beam (Case II), and the two concentrated loads on columns simultaneously with a distributed load on the beam (Case III). The analysis follows using the analytical method by means of the bowing functions, the numerical determination of the buckling load as the least eigenvalue using frame elements, the non-linear analysis allowing for large deformations of the frame elements, the accurate determination of the ultimate load using 3-D finite elements, and the approximate analytical method by using the interaction formula.

The least eigenvalue (Case I), when related to the total frame load, represents the upper bound of the elastic buckling load. The linear and non-linear solutions of the distributed load on the beam (Case II), both give much smaller buckling load values. This value is used to approximate the FEA-accurate solution, by applying the interaction equation. This way has proven to be a safe and accurate solution to the problems encountered with long span portal frames and is strongly recommended for use in the design of portal frames. Precautions must be made to prevent the failure of the frame corner due to excessive shear strains. 


\section{REFERENCES}

1. Hellesland, J., (2007). "Mechanics and effective lengths of columns with positive and negative end restraints". Eng. Struct., Volume (29, No 12), Page (3464-74).

2. Bridge RQ, Fraser DJ, (1986). "Improved G-factor method for evaluating effective lengths of columns". J. Struct. Eng., ASCE, Volume (113, N0. 6), Page (1341-56).

3. Hellesland, J. and Bjorhovde, R., (1996). "Improved frame stability analysis with effective lengths". J. Struct. Eng., ASCE; Volume (122, No. 11), Page (1275-83).

4. Salem, A. H., Elserwi, A. A., El-Dib, F., (2011). "In-plane Stability Considerations of Column Braced Steel Columns", Proc. Annual Int. Stability Conference, SSRCASCE, Pittsburgh, Pennsylvania, May 10-14, Page (227-238).

5. Hellesland, J., (2008). "Approximate second order analysis of unbraced frames reflecting inter-storey interaction in single curvature regions". Research Rep. in Mechanics, No.08-2, Oslo, Norway: Mechanics Division, Dept. of Math., Univ. of Oslo.

6. Hellesland, J., (2012), "Evaluation of effective length formulas and applications in system instability analysis", Journal of the Engineering Structures, Volume (45), Page (405-420).

7. HBRC, (2018). "Design Aids", Giza, Egypt, Housing and Building National Research Center (HBRC).

8. $\quad$ Eurocode 3, (1992). "Design of steel structures", Part 1.1: "general rules and rules for buildings", Brussels: European Committee for Standardisation (CEN).

9. Webber, A., Orr, J.J, Shepherd, P., and Crothers, K. , (2015 ). "The effective length of columns in multi-storey frames", Journal of the Engineering Structures, Volume (102). Page (132-143).

10. El Dib, F.F., (2010). "In- plane stability considerations of trapezoidal steel frameworks", M.Sc. Thesis, Ain Shams University, Cairo, Egypt.

11. Gindy, B.L., (2000). "Validity and accuracy of code interaction formula to check hinged plane frame", M.Sc. Thesis, Ain Shams University, Cairo, Egypt.

12. Salem, A.H., El-Dib F., Elaghouri M., and Hanna, M.T., (2004). "Elastic stability of planar steel frames with unsymmetrical beam loading," J. Struct. Eng, ASCE, Volume (130, No.11), Page (1852-59).

13. ANSYS, (2007 ). "User's guide manual", Release 11. USA: ANSYS Inc;.

14. ECP, (2008). "Egyptian code of practice for the design of steel building - load and resistance factor design" (ECP-205), Giza, Egypt, Housing and Building National Research Center, 